\title{
LEY SOBRE LA APROBACIÓN DE TRATADOS INTERNACIONALES EN MATERIA ECONÓMICA
}

La Ley sobre la Aprobación de Tratados Internacionales en Materia Económica (LSATIME), fue publicada el 2 de septiembre de 2004 en el Diario Oficial de la Federación. Es una ley breve de 14 artículos y dos artículos transitorios organizados en cinco capítulos. El capítulo I trata sobre disposiciones generales; el capítulo II, acerca de los objetivos de la celebración de tratados; el capítulo III trata de los procedimientos de información sobre la celebración de tratados; el IV, de la participación de los poderes de las entidades federativas y de las organizaciones empresariales, ciudadanas y sindicales; y el capítulo $\mathrm{V}$, sobre las disposiciones generales.

La ley, en forma curiosa, es reglamentaria del artículo 93 constitucional en materia de las facultades constitucionales del Senado, de requerir información a los secretarios de Estado, jefes de departamento administrativo, así como a los directores de los organismos descentralizados competentes sobre la negociación, celebración y aprobación de tratados. Decimos en forma curiosa, porque parecería que lo normal sería que fuera reglamentaria del artículo 133 de la Constitución, por ejemplo. Pero, desde otra perspectiva, precisamente el hecho de ser reglamentaria del artículo 93 es significativo, ya que es un signo claro de que el Legislativo tiene por objeto controlar la actividad internacional del Ejecutivo en materia de tratados internacionales, ¿cómo lo hace?, eso es discutible. Con su corta vida, y aun antes de su nacimiento, la LSATIME ya era objeto de críticas profundas. 


\section{I. ¿POR QUÉ UNA NUEVA LEY?}

En efecto, la LSATIME tiene buenas intenciones, en momentos de cambio hay que ir acotando al Poder Ejecutivo en los inmensos poderes que tenía, mediante la intervención efectiva del Senado que, con esta ley trata de controlar y llenar un vacío que la Constitución dejaba. Por ejemplo, en su momento, el Tratado de Libre Comercio de América del Norte fue negociado por un Ejecutivo con excesivos poderes que le permitieron hacer a un lado al Senado, así como a la opinión pública en contrario. El Ejecutivo contaba con amplísimos poderes que le permitían el lujo de desairar los controles del Senado, y con un sistema que estaba caracterizado por su predominio frente al Legislativo.

Por otra parte, lo extraño es que la LSATIME no tomó como base la Ley de Tratados de 1992, que era lo más adecuado. ¿Por qué otra ley?, si lo lógico era retomar el marco constitucional y modificarlo, o bien reformar la Ley de Tratados. Evidentemente, el legislador no pretendió reestructurar todo el sistema de los tratados en nuestro país y referirse sólo a los tratados en materia económica, lo cual es una posición bastante limitada, y podríamos decir, desafortunada, ya que si los tratados en materia económica son muy importantes, no son los únicos que celebra cualquier Estado. Hay tratados tan importantes como los que se celebran para proteger a los derechos humanos o bien aquellos que se celebran para formar parte de los organismos internacionales.

\section{LOS OBJETIVOS DE LOS TRATADOS}

Por supuesto, la importancia y la necesidad de control de los tratados es evidente, y en consecuencia es loable el control que el Senado ejerce en el marco constitucional. Precisamente, hablando de controles, la LSATIME establece ciertos límites, ya que es necesario que se "observen”, para la aprobación de los tratados, dos tipos de objetivos. En realidad, esos objetivos rebasan los fines del mencionado artículo 93 constitucional (artículos 3 y 4).

En principio, los objetivos son de dos caracteres: generales y particulares. Respecto de los generales, algunos son bastante particulares y difíciles de medir, como "contribuir a mejorar la calidad de vida y el nivel de bienestar de la población mexicana", y "propiciar el aprovechamiento de los recursos productivos del país". Sin embargo, puede ser un paráme- 
tro de discusión en el Senado. Objetivos generales, más específicos, son los de "promover el acceso de los productos mexicanos a los mercados internacionales", "contribuir a la diversificación de mercados", "fomentar la integración de la economía mexicana con la internacional y contribuir a la elevación de la competitividad del país, y "promover la transparencia en las relaciones comerciales internacionales y el pleno respeto a los principios de política exterior de la fracción X del artículo 89 de la Constitución Política de los Estados Unidos Mexicanos. Llama la atención este último "objetivo", ya que ante una ambigüedad de la Constitución, la ley aclara que la negociación y la celebración de los tratados internacionales deben hacerse respetando los principios de política exterior. Aquí es donde uno se pregunta por qué no se amplía a todos los tratados internacionales.

Más adelante, la ley contiene un interesante procedimiento sobre la celebración de los tratados (artículo 5) que podría ser muy útil, pero al mismo tiempo podría crear una tramitología que obstaculice la realización de tratados internacionales. Su funcionamiento, en la práctica, dará las pautas para calificar de positivo o negativo de sistema dicho artículo 5. Precisamente de aquí se desprenden las críticas que se hicieron desde el Ejecutivo a esta ley, quien estuvo a punto ejercer su derecho a veto.

La LSATIME es un extraño cuerpo normativo con claras debilidades y una sola fortaleza, los intentos del Legislativo de recomponer el equilibrio de poderes y de hacer partícipe a éste de la responsabilidad de realizar tratados internacionales.

Manuel BECERRA RAMÍREZ*

* Investigador del Instituto de Investigaciones Jurídicas de la UNAM. 
LEY SOBRE LA APROBACIÓN DE TRATADOS
INTERNACIONALES EN MATERIA ECONÓMICA

CAPÍTULO I

DISPOSICIONES GENERALES

Art. 1. Esta ley es de orden público y tiene como objeto reglamentar el artículo 93 de la Constitución General de la República en materia de las facultades constitucionales del Senado de requerir información a los secretarios de Estado, jefes de departamento administrativo, así como a los directores de los organismos descentralizados competentes sobre la negociación, celebración y aprobación de tratados relacionados con el comercio de mercancías, servicios, inversiones, transferencias de tecnología, propiedad intelectual, doble tributación, cooperación económica y con las demás materias a que se refiere este ordenamiento cuando se relacionen con las anteriores.

Art.2. Para los efectos de esta ley se entenderá por tratados lo establecido por la Ley Sobre la Celebración de Tratados.

Estarán de acuerdo con la Constitución General de la República respetando:

I. Las garantías individuales, y

II. La división de poderes, la distribución de facultades y las potestades de los órganos representantes del pueblo.

\section{CAPÍTULO II}

DE LOS OBJETIVOS DE LA CELEBRACIÓN DE TRATADOS

\section{SECCIÓN I \\ DE LOS OBJETIVOS GENERALES}

Art. 3. Para la aprobación de un tratado se observarán los siguientes objetivos generales:

I. Contribuir a mejorar la calidad de vida y el nivel de bienestar en la población mexicana.

II. Propiciar el aprovechamiento de los recursos productivos del país.

III. Promover el acceso de los productos mexicanos a los mercados internacionales.

IV. Contribuir a la diversificación de mercados.

V. Fomentar la integración de la economía mexicana con la internacional y contribuir a la elevación de la competitividad del país. 
VI. Promover la transparencia en las relaciones comerciales internacionales y el pleno respeto a los principios de política exterior de la fracción $\mathrm{X}$ del artículo 89 de la Constitución Política de los Estados Unidos Mexicanos.

\title{
SECCIÓN II \\ OBJETIVOS PARTICULARES
}

Art. 4. Para la aprobación de un tratado se observará congruencia con los siguientes objetivos particulares según proceda:

I. En materia de solución de controversias:

a. Otorgar a los mexicanos y extranjeros que sean parte en la controversia el mismo trato conforme al principio de reciprocidad internacional;

b. Asegurar a las partes la garantía de audiencia y el debido ejercicio de sus defensas,

c. Garantizar que la composición de los órganos de decisión aseguren su imparcialidad.

II. En materia de prácticas desleales de comercio exterior:

a. Fomentar la libre concurrencia y buscar las sanas practicas de competencia,

b. Prever y promover mecanismos para contrarrestar los efectos de las prácticas desleales de comercio de los países con lo que se contrate,

III. Fomentar el respeto de los derechos de propiedad intelectual;

IV. Impulsar el fomento y la protección recíproca de las inversiones y las transferencias de tecnología, generación, difusión y aplicación de los conocimientos científicos y tecnológicos que requiere el desarrollo nacional;

V. Impulsar la eliminación o reducción de obstáculos innecesarios al comercio que sean incompatibles con la ley y con los compromisos internacionales;

VI. Prever que las normas de los tratados consideren las asimetrías diferencias y desequilibrios así como las medidas correspondientes para compensarlas, y

VIII. Los demás objetivos que corresponden a la naturaleza del tratado.

\author{
CAPÍTULO III \\ DE LOS PROCEDIMIENTOS DE INFORMACIÓN \\ SOBRE LA CELEBRACIÓN DE TRATADOS
}

Artículo 5. Al inicio de cada periodo ordinario de sesiones, el Senado, a través de las comisiones competentes, requerirá un informe a las secretarías de Estado y a cualquier organismo de la administración pública fede- 
ral que represente a México sobre el inicio de negociaciones formales de un tratado. El informe contendrá:

I. Las razones para negociar así como las consecuencias de no hacerlo;

II. Los beneficios y ventajas que se espera obtener de la negociación y la expectativa de cumplir con los objetivos de esta ley que correspondan conforme al tratado que se pretende celebrar, y

III. Un programa inicial del proceso de negociación calendarizado.

Las comisiones a las que se turne el informe podrán crear, por cada tratado, una subcomisión plural para dar un seguimiento, proponer acciones legislativas, recabar y obtener información sobre el estado que guardan las negociaciones, entrevistar a servidores públicos, representantes de grupos de interés, peritos o cualquier persona que pueda aportar conocimientos y experiencias sobre las negociaciones.

Artículo 6. Con base en la información sobre el avance de las negociaciones las comisiones a las que y haya sido turnado el informe, o en su caso, la subcomisión a la que se refiere el artículo anterior, deberán requerir a las Secretarías de Estado y al cualquier organismo de la Administración Pública Federal que represente a México en las negociaciones, con la anticipación necesaria a la fecha determinada para la firma del tratado correspondiente, un informe sobre el resultado final completo de las negociaciones, y sobre la forma en que se atendieron los objetivos de esta ley.

Asimismo, el informe contará con una explicación amplia y detallada de:

I. Los beneficios que se obtuvieron en la negociación,

II. Los alcances de la negociación,

III. Los compromisos de la negociación, y

IV. Las normas legales y administrativas que tendrían que modificarse de acuerdo con el tratado.

Artículo 7. El Senado de la República con base en la información a que se refiere el artículo anterior y de conformidad con los artículos 58 y 59 del Reglamento para el Gobierno interior del Congreso general de los Estados Unidos Mexicanos, emitirá si lo considera necesario, un punto de acuerdo, relativo al contenido del informe.

Artículo 8. En el periodo, comprendido entre las fases señaladas en los artículos 5 y 6 de la presente ley, las secretarias de Estado y cualquier organismo de la Administración Pública Federal encargado de la representación de México en las negociaciones deberán presentar informes periódicos con base en el programa inicial al que se refiere la fracción II del artículo 5, a las comisiones legislativas a las que haya sido turnado el informe de inicio de negociaciones, o en su caso, a las subcomisión correspondiente. 
Las comisiones, o en su caso la subcomisión, estarán facultadas para requerir y obtener la información mencionada. Podrán allegarse de estudios que realice el personal a su cargo o los que requieran a las dependencias competentes del Poder ejecutivo.

Las comisiones, o en su caso las subcomisión podrá citar a comparecencia a las y los funcionarios señalados.

Artículo 9. Para la aprobación de algún tratado ya firmado deberá someterse al Senado junto con los siguientes documentos:

I. Un escrito con todas las acciones administrativas para aplicar los objetivos que correspondan conforme al tratado de que se trate;

II. Una explicación de cómo la aprobación del tratado afectará las leyes y reglamentos de México,

III. Los rubros que México concedió durante la negociación;

IV. La forma en que se cumplirán los objetivos que correspondan conforme al tratado firmado;

$\mathrm{V}$. La manera en que le tratado cumple con los intereses de México, y

VI. Las reservas que los países miembros del tratado establecieron y las razones.

Artículo 10. Para la aprobación a que se refiere el artículo anterior de la presente Ley, el Senado de la República, o en su caso la comisión permanente deberán tomar el tratado alas comisiones competentes, en la sesión siguiente a la fecha en que el ejecutivo federal lo haya sometido al Senado.

\section{CAPÍTULO IV}

DE LA PARTICIPACIÓN DE LOS PODERES DE LAS ENTIDADES

FEDERATIVAS Y DE LAS ORGANIZACIONES EMPRESARIALES, CIUDADANAS Y SINDICALES

Artículo 11. Sin distinción alguna los ciudadanos y las organizaciones empresariales, ciudadanas y sindicales podrán emitir su opinión ante el Senado de la República.

Las comunicaciones entre ciudadanos, organizaciones y las comisiones correspondientes podrán ser orales en audiencia o por escrito en todo caso, serán publicas, salvo disposición legal en contrario.

Artículo 12. El Senado de la República, a través de sus comisiones, escuchará y tomara en cuenta las propuestas que le hagan llegar o que presenten los gobiernos y congresos locales. 


\section{CAPÍTULO V \\ DISPOSICIONES GENERALES}

Artículo 13. Para el cálculo de los plazos y términos que fija esta ley se entiende por días hábiles todos los días exceptuando los sábados y domingos así como los días que establece el artículo 74 de la Ley Federal del Trabajo.

Artículo 14. En todo lo no dispuesto por la presente ley se aplicarán supletoriamente la Ley de Comercio Exterior, la Ley sobre la Celebración de Tratados y los demás ordenamientos que resulten aplicables.

\section{ARTÍCULOS TRANSITORIOS}

PRIMERO. La presente Ley entrará en vigor al día siguiente de su publicación en el Diario Oficial de la Federación.

SEGUNDO. En el caso de que el Ejecutivo Federal haya iniciado negociaciones deberá atender el requerimiento de información en los términos del artículo 5 junto con los avances de las mismas conforme a las disposiciones aplicables del artículo 6 de la presente ley. 